\title{
Microvessel density as new prognostic marker after radiotherapy in
} rectal cancer

\author{
Saulius Svagzdys*1, Vaiva Lesauskaite ${ }^{\dagger 2}$, Dainius Pavalkis ${ }^{\dagger 1}$, \\ Irena Nedzelskiené ${ }^{\dagger 4}$, Darius Pranys ${ }^{\dagger 3}$ and Algimantas Tamelis ${ }^{\dagger 1}$
}

\author{
Address: ${ }^{1}$ Unit of Coloproctology, Department of Surgery, Kaunas Medical University Clinics, Eiveniu 2, Kaunas, Lithuania, ${ }^{2}$ Institute of \\ Cardiology, Kaunas University of Medicine, Kaunas, Lithuania, ${ }^{3}$ Clinic of Pathological Anatomy, Kaunas University of Medicine, Kaunas, \\ Lithuania and ${ }^{4}$ Clinic of Dental and Oral Pathology, Kaunas University of Medicine, Kaunas, Lithuania \\ Email: Saulius Svagzdys* - s.svagzdys@gmail.com; Vaiva Lesauskaite - vaiva.lesauskaite@med.kmu.lt; \\ Dainius Pavalkis - dainius.pavalkis@kmuk.lt; Irena Nedzelskienė - irenaned@med.kmu.lt; Darius Pranys - patkmuk@kmu.lt; \\ Algimantas Tamelis - kp@kmuk.lt \\ * Corresponding author †Equal contributors
}

Published: 26 March 2009

BMC Cancer 2009, 9:95 doi:10.1/86/147/-2407-9-95
Received: 10 July 2008

Accepted: 26 March 2009

This article is available from: http://www.biomedcentral.com/I47/-2407/9/95

(C) 2009 Svagzdys et al; licensee BioMed Central Ltd.

This is an Open Access article distributed under the terms of the Creative Commons Attribution License (http://creativecommons.org/licenses/by/2.0), which permits unrestricted use, distribution, and reproduction in any medium, provided the original work is properly cited.

\begin{abstract}
Background: The extent of angiogenesis is an important prognostic factor for colorectal carcinoma, however, there are few studies concerning changes in angiogenesis with radiotherapy (RTX). Our aim was to investigate changes in tumor angiogenesis influenced by radiotherapy to assess the prognostic value of angiogenesis the microvessel density (MVD) in overall survival after radiotherapy.
\end{abstract}

Methods: Tumor specimens were taken from $10 \mathrm{I}$ patients resected for rectal cancer. The patients were divided into three groups according to the treatment they received before surgery (not treated, a short course, or long course of RTX). Tumor specimens were paraffin-embedded and immunohistochemistry was performed with primary antibody against CD-34 to count MVD.

Results: MVD was significantly lower in the group of patients treated with a long course of RTX ( $p<0.025$ ). The mean MVD for the long RTX group was 134.8; for the short RTX group - 192.5; and for those not treated with RTX - 193.0. There were no significant statistical correlations between MVD and age, sex, grade of tumor differentiation $(G)$ and tumor size $(T)$ in those untreated with RTX. In long RTX group we found a significant prognostic rate for MVD when the density cut off was near 130 with $92.3 \%$ sensitivity and $64.7 \%$ specificity. When the MVD was lower than a cut off of 130 , the survival period significantly increased $(p=0.001)$, the mortality rate is significantly higher if the MVD is higher than 130 (microvessel/ $\left.\mathrm{mm}^{2}\right)(1953.047 ; \mathrm{p}=0.002)$, if the histological grade is moderate/poor $(127.407 ; p=0.013)$, if the tumor is T3/T4 $(111.618 ; p=0.014)$, and if the patient is male $(17.92 ; p=0.034)$ adjusted by other variable in model.

Conclusion: Our results show that a long course of radiotherapy significantly decreased angiogenesis in rectal cancer tissue. MVD was found to be a favourable marker for tumor behaviour during RTX and a predictor of overall survival after long course of RTX. Further investigations are now needed to determine the changes in angiogenesis during a shorter course of RTX. 


\section{Background}

Colorectal cancer (CRC) is the third most common cancer and the fourth most frequent cause of cancer deaths worldwide [1]. CRC is a disease of the elderly, with only $5 \%$ of cases recorded in those younger than 40 years of age [2]. CRC is commonly found to be rectal cancer (RC). The main prognostic factors in $\mathrm{RC}$ are the size of the tumor $(\mathrm{T})$, lymph node metastases $(\mathrm{N})$ and grade of tumor differentiation (G) [3]. These factors are important for clinical staging and treatment. Preoperative radiotherapy with total mesorectal excision surgery improves local control, but has no statistically-significant impact on overall survival [4]. An efficient adjuvant treatment is necessary to further reduce the development of distant metastases and to improve overall survival. By contrast, preoperative chemoradiotherapy in terms of local control compared with radiotherapy alone is now proven in locally advanced rectal cancer, but overall survival is not yet modified by preoperative chemotherapy [5]. However little is known about the effects of radiation on endothelial cell behavior within these human tumors after radiotherapy (RTX). It is conceivable that RTX could diminish both proliferation and function of these endothelial cells (EC).

Common prognostic factors do not fully predict individual clinical outcomes especially among patients with tumors of stage II and III. The response of clinically-identical tumors to the same treatment may be vastly different. Therefore, to improve clinical care and to give an optimal treatment, biological prognostic markers must be identified [6]. The relationship between tumor angiogenesis with the grade of tumor differentiation, its metastatic potential and prognosis for survival has been proven [1]. Formation of new blood vessels from the endothelium of the existing vasculature is essential in angiogenesis [7]. The angiogenic process depends upon the balance between many stimulatory and inhibitory factors. Proangiogenic factors, such as vascular endothelial growth factor (VEGF), bind to sites on endothelial cells that lead to their proliferation. Microvessel density (MVD) is a surrogate marker which expressly reflects tumor angiogenesis and has been examined as a potential prognostic marker in numerous tumors [8]. The aim of our study was to investigate the changes in tumor angiogenesis under the influence of different types of radiotherapy to assess the prognostic value of angiogenesis (MVD) in the overall survival after radiotherapy.

\section{Methods}

\section{Patients and tumor specimens}

In this retrospective study, we assessed paraffin-embedded specimens from tumors from 101 patients resected for rectal cancer from January 2000 to December 2003. This study included patients with resectable rectal carcinoma. The exclusion criteria were a synchronous tumor or tumors in another localisation in anamnesis, or emergency surgery. The age of the patients was $69.4 \pm 0.9$ (ranging from 36 to 87 years of age); for males, the mean age was $68.7 \pm 1.1(\mathrm{n}=60)$, for females, mean age was $70.4 \pm$ $1.5(n=41)$ years of age. All patients had confirmed rectal adenocarcinomas by histopathology and were staged according to the 5th edition of the American Joint Committee on Cancer (AJCC) Staging Manual [9]. All of the patients underwent radical low anterior or abdominperineal rectum resections. The patients were then divided into three groups according to the radiotherapy they had received before surgery. The first group $(n=57)$ only underwent surgery (no RTX), the second $(n=16)$ had 25 Gy short course radiotherapy (short RTX) and surgery, the third group $(\mathrm{n}=28)$ had $48-52$ Gy long course radiotherapy (long RTX) and surgery. The no RTX and short RTX group patients had clearly resectable tumors and a nodal status according to endorectal ultrasound examination was N0. Young-age patients and those with higher risk of disease recurrence (tumor differentiation grade etc.) with T3-T4 received short RTX. The patients with pretreatment nodal status $\mathrm{N} 1$ by endorectal ultrasound or with unresectable T4 rectal tumors composed the long RTX group. All patients were followed up $42.6 \pm 1.9$ month after the operation for rectal cancer. The Lithuanian Cancer Register supplied the date and cause of death of those who died during the follow-up period. According to this information, study subjects were grouped as to those who survived or failed to survive during follow-up.

\section{Radiotherapy}

A SIEMENS "MEVATRON M" 15 MV linear accelerator was used. Three dimensional conformal radiotherapy was used for all patients based on a contrast CT scan of the pelvis. The four fields "box" technique was used. For short RTX group patients, irradiation was given in a dose of $5 \mathrm{~Gy}$ five fractions within five days. Surgical resection was performed within a week after RTX. For long RTX group patients, irradiation was given in a dose of $50 \mathrm{~Gy} / 5$ weeks with 2 Gy fraction treating 5 days/week. Surgical resection was performed within six - eight weeks after RTX.

\section{Immunohistochemistry}

Paraffin-embedded specimens were sectioned in $3 \mu \mathrm{m}$ slices and mounted on glass slides. De-paraffinization and re-hydration was performed by a slide stainer Varistain Gemini (ThermoShendon). Then, sections were washed with distilled water and heated in TRIS/EDTA buffer $(\mathrm{pH}$ 9.0) for 8 minutes at $110^{\circ} \mathrm{C}$ in a Microwave Histoprocessor RHS-1 (Milestone, Microwave Laboratory Systems). Immunochistochemistry was performed by the Shandon Coverplate system. After blocking endogenous peroxidase activity, all slides were incubated in the primary antibody directed towards CD-34 for 1 hour at a dilution of 1:100 in Antibody Diluent (DakoCytomation), followed by 
sequential 30 minutes incubations with Advance ${ }^{\mathrm{TM}}$ HRP Link and Advance ${ }^{\mathrm{TM}}$ HRP Enzyme (DakoCytomation). The binding reaction was detected by the Liquid $\mathrm{DAB}+$ Substrate Chromogen System (DakoCytomation). Finally, the sections were counterstained with Mayer's hematoxylin (J.T.Baker), and mounted using xylene-based mounting medium Consul-Mount ${ }^{\mathrm{TM}}$ (Shandon).

\section{Evaluation of MVD}

Slides stained with anti-CD34 monoclonal antibody were examined with an Olympus BX 61 light microscope. Single endothelial cells or clusters of endothelial cells positive for CD-34 were considered as a vessel. The presence of blood cells or fibrin without any detectable endothelial cells was not sufficient to define a microvessel. Vessels with muscular walls were not counted. At first, slides were examined at an original magnification of $4 \times$. Three "hot spots" (areas with the highest microvessel concentration) from each slide were identified and these areas were photographed by a digital Olympus DP-70 camera at an original magnification of $10 \times$. The area of this histological field was 576,207 $\mu \mathrm{m}^{2}$. Two independent observers with an Image - Pro AMS 6.0.0 program counted the number of microvessels in the histological field. MVD (microves$\mathrm{sel} / \mathrm{mm}^{2}$ ) was then assessed according to Weidner et al. [10]. MVD of the specimen was estimated as a mean of MVD in three histological fields (Figure 1).

\section{Statistical analysis}

For statistical analysis, SPSS version 13 (SPSS Inc., Chicago, IL) was used. The Students independent samples ttest, and ANOVA were used to compare means in groups. We used the Bonferoni test to compare multiple pairs. It was used as a precise or asymptomatic significance test

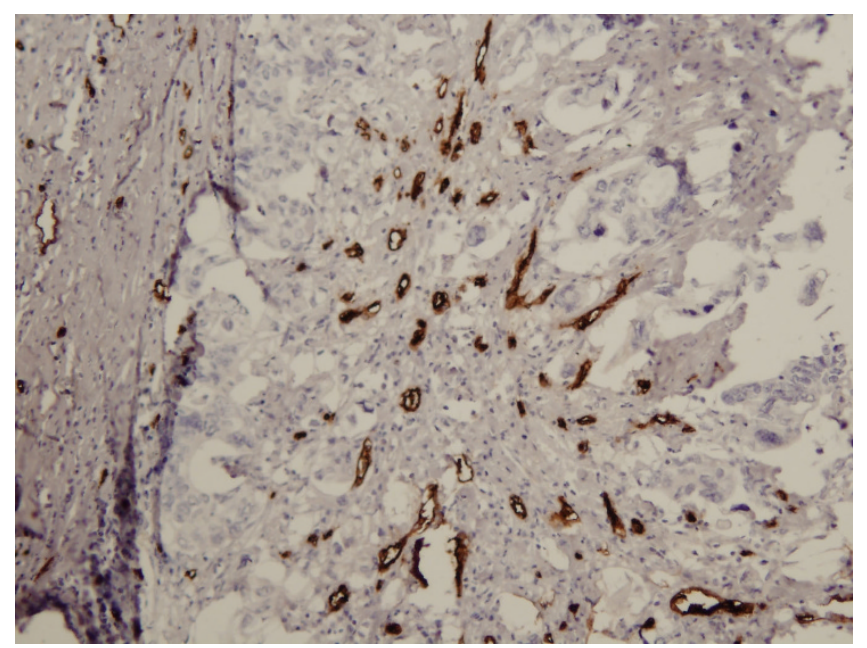

\section{Figure I}

The "hot spot" (original magnification $\times 10)$. MVD is $133 \mathrm{microvessel} / \mathrm{mm}^{2}$. due to the size of the samples. The ROC curves method was used to establish critical MVD value and later sensitivity and specificity of this parameter to predict the lethality issue. Survival curves were estimated by the Kaplan-Meier method and compared by the Mantel (log rank) test. Prognostic factors of survival were identified by the use of the Cox proportional hazard model. $\mathrm{p}<0.05$ was considered to be statistically significant.

\section{Ethical approval}

The study was approved by Kaunas Regional Ethics Committee for Biomedical Research (protocol No.: 134/2006)

\section{Results}

The main clinical data of the patients are summarized in Table 1 . There was no statistically- significant difference between the groups according to age, sex, tumor $\mathrm{T}$ and death. The tumor $\mathrm{T}$ was higher and metastases in lymph nodes were more frequent in the group that had received no RTX as compared to the long RTX treatment group. This phenomenon was due to a radiotherapy downstaging effect.

\section{Microvessel Density}

The mean MVD in the no RTX, the short RTX and the long RTX groups was respectively $193.0 \pm 11.2,192.5 \pm 16.2$ and $134.8 \pm 7.0$ vessel $/ \mathrm{mm}^{2}(\mathrm{~F}=6.726 ; \mathrm{df}=2 ; \mathrm{p}=0.002)$. The MVD was significantly lower in the samples from patients who had received the long course of RTX before operation (Figure 2).

\section{Long course RTX group}

There was no significant difference in the MVD according to gender, T, N, and G in the long RTX group (Table 2).

The patients who underwent long RTX and survived during the survey demonstrated significantly smaller MVD in tumor specimens and had lower lymph node metastatic rates in comparison to the patients who died during the survey. The mean MVD was $117.6 \pm 5.8$ vs. $161.2 \pm 11.6$ microvessel $/ \mathrm{mm}^{2},(\mathrm{p}=0.001)$ and lymph node metastatic rate was $11.8 \%$ vs $45.5 \%(\mathrm{p}<0.05)$, respectively (Figure 3, Table 3).

The ROC test was made to discover the MVD cut-off which displayed a high risk of mortality after long RTX (Figure 4). The cut-off is $130 \mathrm{microvessel} / \mathrm{mm}^{2}$. We obtained $90.9 \%$ sensitivity and $70.6 \%$ specificity of MVD when the cut-off is 130 .

According to the Kaplan-Meier method and as compared by the Mantel (log rank) test, the survival period tended to be longer when the tumor $\mathrm{T}$ was lower, there were no lymph node metastases, the tumor differentiation grade was better and the patient was female. The survival curve 
Table I: Clinical Data of Patient Groups Investigated

\begin{tabular}{|c|c|c|c|}
\hline & \multicolumn{3}{|c|}{ Treatment Groups } \\
\hline & $\begin{array}{l}\text { No RTX } \\
(\mathrm{n}=57)\end{array}$ & $\begin{array}{l}\text { Short RTX } \\
(n=16)\end{array}$ & $\begin{array}{l}\text { Long RTX } \\
(\mathrm{n}=28)\end{array}$ \\
\hline Age $M \pm S E$, years & $71.2 \pm 1.2$ & $66.0 \pm 2.3$ & $67.6 \pm 1.6$ \\
\hline \multicolumn{4}{|l|}{ Sex, \% } \\
\hline Male & 45.6 & 43.8 & 28.6 \\
\hline Female & 54.4 & 56.3 & 71.4 \\
\hline \multicolumn{4}{|l|}{ Tumor, \% } \\
\hline $\mathrm{pT} / \mathrm{T} 2$ & 22.8 & 37.5 & 35.7 \\
\hline $\mathrm{pT} 3 / \mathrm{T} 4$ & 77.2 & 62.5 & 64.3 \\
\hline \multicolumn{4}{|c|}{ Lymph node metastases (pN), \% } \\
\hline Absent & 50.9 & 56.3 & 75 \\
\hline Present & 49.1 & 43.7 & 25 \\
\hline \multicolumn{4}{|c|}{ Histological grade (pG), \% } \\
\hline Very well/well & 66.7 & 37.5 & 60.7 \\
\hline Moderate/poor & 33.3 & 62.5 & 39.3 \\
\hline Mortality Rate, \% & 42.1 & 18.8 & 39.3 \\
\hline
\end{tabular}

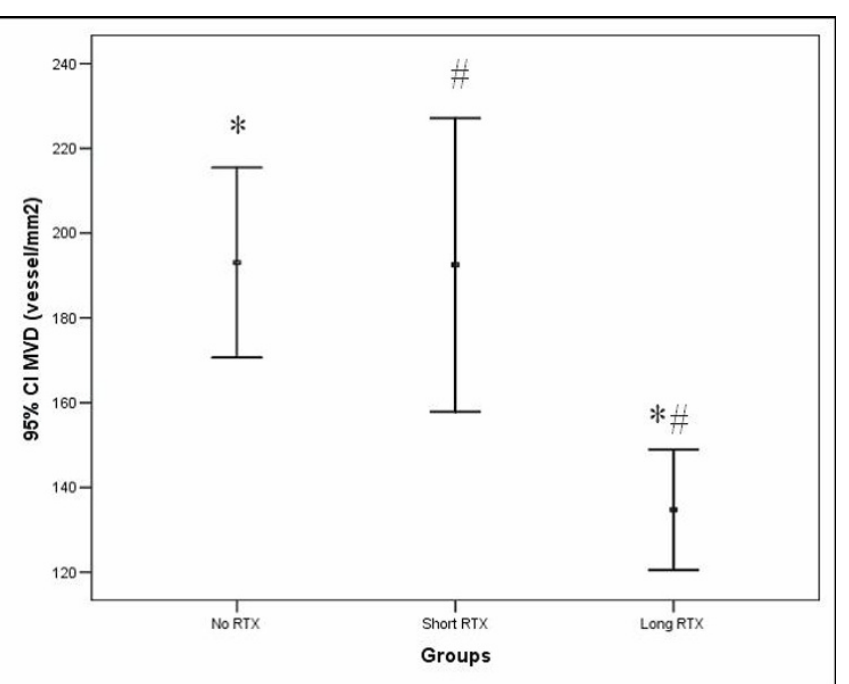

Figure 2

Differences of mean \pm SE of MVD (microvessel/mm2) in untreated (no RTX), short term (short RTX) and long term RTX (long RTX) groups. F = 6.726; $\mathrm{df}=2$; $\mathrm{P}^{*}$ $=0.002, p^{\#}=0.034$.

also showed a statistically-significant relationship between microvessel density and the survival period. When the MVD was lower than a cut off of 130, the survival period significantly increased $(\mathrm{p}=0.001)$ (Figure 5). According to the Cox logistic proportional regression model, the mortality rate is significantly higher if the MVD is higher than 130 (vessel $\left./ \mathrm{mm}^{2}\right)(1953.047$; $\mathrm{p}=$ $0.002)$, if the histological grade is moderate/poor (127.407; $\mathrm{p}=0.013)$, if the tumor is T3/T4 $(111.618 ; \mathrm{p}=$ $0.014)$, and if the patient is male $(17.92 ; \mathrm{p}=0.034)$ adjusted by other variable in model. (Table 4 ).

\section{Discussion}

Angiogenesis plays an important role in tumorogenesis and metastatic processes. There are few studies done that investigate the RTX influence on angiogenesis. Aside from direct tumor cytotoxic effects, RTX may also influence other physiologic parameters that are known to be important in colorectal cancer. In particular, little is known about the response of angiogenesis to this therapy. Increased type-IV collagenase activity (MMP-2 and MMP9) following preoperative RTX in rectal cancer was recently discovered [11]. It is of note that these MMP participate in angiogenesis [12]. Increased MMP-2 activity was also reported in colon carcinoma and in osteosarcoma cell lines after 5 Gy of radiation at short time periods of up to $24 \mathrm{~h}$. [13]. This evidence shows that RTX may temporarily increase the invasive potency of the tumor that leads to micrometastases or split tumor cells at the time of surgery [14]. According to Baeten et al. [15] RTX inhibits proliferation of EC despite a high percentage of residual EC in tumor tissue after prolonged RTX. This suggests a higher sensitivity of non-endothelial cells to RTX leading to a greater percentage of loss of these cells. MVD is one of the parameters that assesses the outcome of all 
Table 2: Microvessel density (MVD) in relation to gender, $T, \mathbf{N}$ and tumor differentiation grade in the long term $\mathbf{R T X}$ group.

\begin{tabular}{|c|c|c|}
\hline & MVD M \pm SE (microvessel/mm2) & $\mathbf{p}$ \\
\hline \multicolumn{3}{|l|}{ Gender } \\
\hline Male & $131,46 \pm 10.2$ & 0,48 \\
\hline Female & $136,07 \pm 8.9$ & \\
\hline \multicolumn{3}{|l|}{ Tumor } \\
\hline $\mathrm{pTI} / \mathrm{T} 2$ & $145,9 \pm 14,2$ & 0,38 \\
\hline $\mathrm{pT} 3 / \mathrm{T} 4$ & $128,56 \pm 7,4$ & \\
\hline \multicolumn{3}{|c|}{ Lymph node metastases $\mathrm{pN}$} \\
\hline Absent & $134.4 \pm 8,8$ & 0,48 \\
\hline Present & $135.9 \pm 10,1$ & \\
\hline \multicolumn{3}{|c|}{ Histological grade $p G$} \\
\hline Very well/well & $134,4 \pm 7,6$ & 0,33 \\
\hline Moderate/poor & $135,3 \pm 13,7$ & \\
\hline
\end{tabular}

Table 3: Clinical Data of the Patients who received a long course of radiotherapy

\begin{tabular}{llll}
\hline & $\begin{array}{l}\text { Survived } \\
(\mathrm{n}=\mathrm{I})\end{array}$ & $\begin{array}{l}\text { Deceased } \\
(\mathrm{n}=\mathrm{II})\end{array}$ & $\mathrm{P}$ \\
\hline Age M \pm SE, years & $67.5 \pm 1.9$ & $67.8 \pm 2.9$ & 0.64 \\
\hline MVD M \pm SE, microvessel/mm² & $117.6 \pm 5.8$ & $161.2 \pm 11.6$ & 0.001 \\
\hline $\begin{array}{l}\text { Sex, \% } \\
\text { Male }\end{array}$ & 35.3 & 18.2 & 0.3 \\
Female & 64.7 & 81.8 & \\
\hline $\begin{array}{l}\text { Tumor, \% } \\
\text { PTI/T2 }\end{array}$ & & & \\
PT3/T4 & 41.2 & 27.3 & 0.45 \\
\hline $\begin{array}{l}\text { Lymph node metastases (pN), \% } \\
\text { Absent }\end{array}$ & 58.8 & 72.7 & \\
$\begin{array}{l}\text { Present } \\
\text { Histological grade (pG), \% }\end{array}$ & 88.2 & 54.5 & 0.044 \\
$\begin{array}{l}\text { Very well/well } \\
\text { Moderate/poor }\end{array}$ & 64.7 & 54.5 & \\
\hline
\end{tabular}

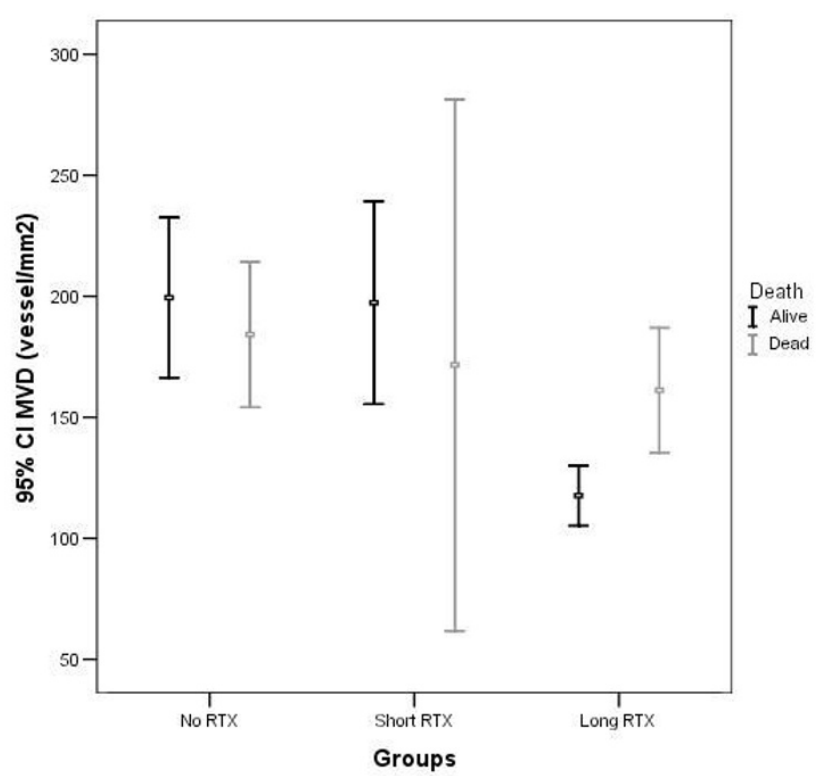

Figure 3

Distribution between mean \pm SE of MVD (microvessel/mm2) and survival in untreated (no RTX), short term (short RTX) and long term RTX (long RTX) groups. 
the processes. Our results demonstrate that long RTX pretreatment significantly decreased MVD in tumor tissue. Treatment using short RTX did not change the mean MVD as compared to tumor samples taken from those receiving no RTX; the only feature noticeable was that the dispersion of MVD was greater in a short RTX group as compared to no RTX group. It is of note that tumor samples from the short RTX group were taken one week after the radiation treatment. This suggests that the changes in the tumor tissue may be subsequent to the cytotoxic effects of RTX that lead to inflammation that begins in the tumor straight after RTX [16]. It was demonstrated that RTX upregulated expression of adhesion molecules on endothe-

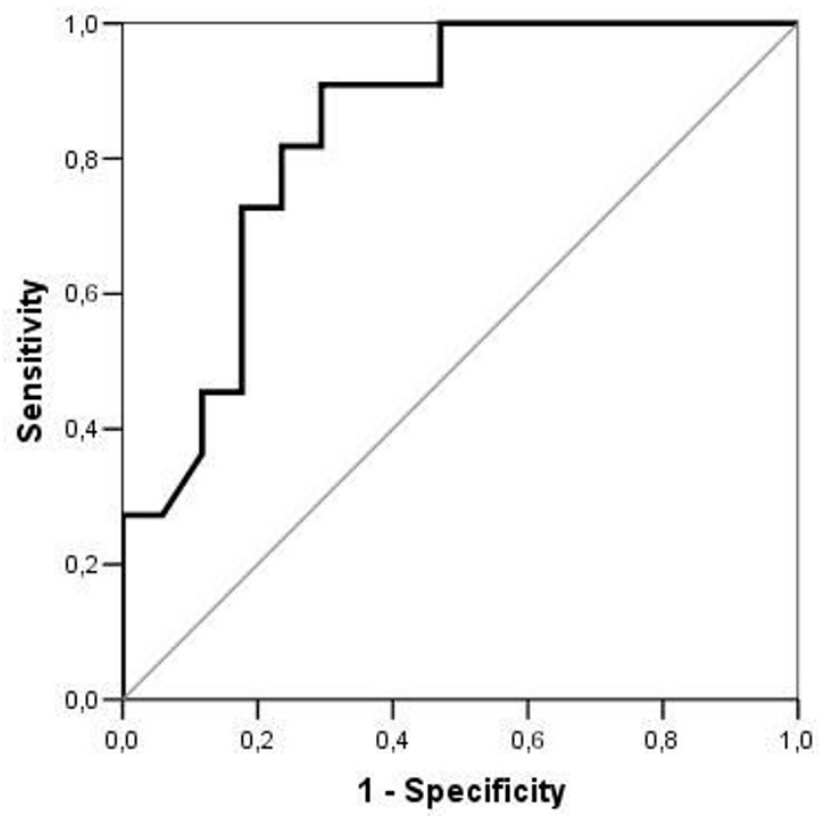

Figure 4

Diagram of ROC curves for patients who received long course of radiotherapy. Area $84.2 \%$; $=0.003$.

Table 4: Multivariate Cox proportional hazard analysis for mortality

\begin{tabular}{llll}
\hline & Relative risk (B) & $95 \%$ Cl for $\operatorname{Exp}(\mathrm{B})$ & $\mathrm{P}$ \\
\hline MVD $(130 \mathrm{ir}>)$ & 1953.047 & $14.816-257444.0$ & 0.002 \\
\hline Age & 0.96 & $0.864-1.066$ & 0.446 \\
\hline Gender & 17.92 & $1.243-258.432$ & 0.034 \\
\hline Tumor & 111.618 & $2.578-4833.392$ & 0.014 \\
\hline Lymph node metastases & 3.34 & $0.293-38.061$ & 0.331 \\
\hline Histological grade & 127.407 & $2.774-5852.496$ & 0.013
\end{tabular}

lial cells, and as a result stimulated infiltration of leukocytes into tumor tissue. The increase in expression of EC adhesion molecules and of leukocyte infiltration after RTX suggests the activation of a local antitumor reaction [15]. The tumor samples from the patients that received a long course of RTX were taken $6-8$ weeks after the RTX. During this period, cytotoxic effects and the inflammatory reaction induced by radiation treatment in the tumor tissue is diminishing, radiation induced necrotic lesions of the tumor are repaired by fibrous connective tissue [17]. We might speculate that neoplastic cells have less opportunity to invade surrounding tissue during surgery when MVD was decreased. Decreased invasion of neoplastic cells into surrounding tissues leads to a diminished local rate of recurrence of the tumor after preoperative RTX. In spite of this, the overall survival of the patients assigned to radiotherapy and surgery or assigned to surgery alone is similar [4]. This phenomenon can be explained by the development of distal metastases which might have spread at the beginning of RTX when expression of MMP and other angiogenic factors are increased $[18,19]$.

In our study, we had limitation in sample size. We had enrolled all patients underwent surgery for rectal carcinoma in our surgical department during four years period. One third of patients underwent emergency operations or had tumors of another localisation (exclusion criteria). Another part had incomplete clinical data or unclear outcome of disease due to missing from follow-up. Some part of the patients was excluded because of the difficulties preparing the high quality slides from paraffin-embedded specimens. These reasons probably could have limited the reveal of statistically significant relationship between MVD and other prognostic markers such as tumor T, N, G. So our findings disagree with the findings of Gallego et al. They proved a relationship between MVD, G, N and the prognosis for survival $[20,21]$. Such a difference may be explained by the impact of the RTX on tumor angiogenesis. We demonstrated that there was a significant differ- 


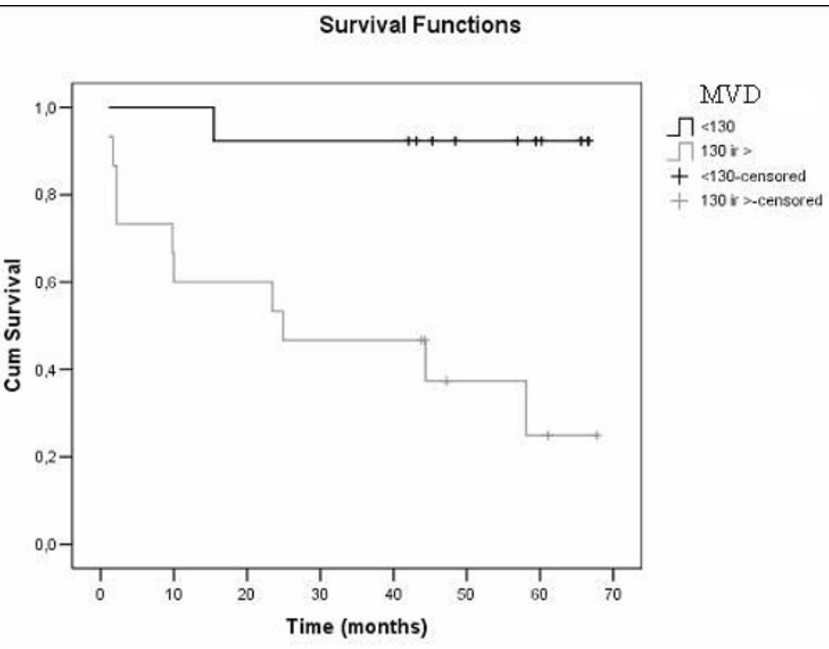

Figure 5

Overall survival in subjects with a cut-off $<130$ versus cut-off $>$ I 30. Log rank test: $p=0.00$ I.

ence in MVD between patients who survived and those who did not survive during follow-up after combined treatment of a long course RTX and surgery. Thus MVD and the overall survival relationship discovered in our study indicates perhaps that a high MVD after a long course of RTX may show tumor resistance to radiotherapy in those tumor samples taken from patients who did not survive in comparison to those who did survive. This might indicate tumor resistance to RTX in a subset of tumors. According to Shia et al., recurrence-free survival time is better in patients with a fibrotic-type of stromal response with minimal inflammatory infiltrates [22]. MVD and the overall survival relationship discovered in our study indicates that high MVD after long RTX may show a high tumor resistance to radiotherapy.

\section{Conclusion}

Our study using MVD in long course RTX reveals a very defined cut off and appears to have great prognostic potential. Based on the MVD changes, tumor response to RTX and individualized treatment could be evaluated. Further investigations are needed to uncover any changes in angiogenesis and in the inflammatory reaction during radiotherapy.

\section{Competing interests}

The authors declare that they have no competing interests.

\section{Authors' contributions}

SS conceived of the study, abstracted data, participated in assessement of histological fields, drafted and revised the manuscript. VL carried out the immunoassays, assessed histological fields, participated in the design of the study and helped to draft and approved the final manuscript. DP and AT participated in the planning and the design of the study, and in the analysis and discussion of the results. IN performed the statistical analysis. DPr carried out histopathological analyses and established pathological diagnosis. All authors read and approved the final manuscript.

\section{Acknowledgements}

This work was supported in part by Lithuanian State Science and Studies Foundation. We thank Lithuanian Cancer Registry for providing epidemiological data for our study. Also we thank George Markelionis for editorial help.

\section{References}

I. Des GG, Uzzan B, Nicolas P, Cucherat M, Morere JF, Benamouzig R, et al:: Microvessel density and VEGF expression are prognostic factors in colorectal cancer. Meta-analysis of the literature. Br J Cancer 2006, 94: 1823-1832.

2. Latkauskas T, Rudinskaite G, Kurtinaitis J, Janciauskiene R, Tamelis A, Saladzinskas Z, et al.: The impact of age on post-operative outcomes of colorectal cancer patients undergoing surgical treatment. BMC Cancer 2005, 5:153.

3. Jass JR: Pathogenesis of colorectal cancer. Surg Clin North Am 2002, 82:89I-904.

4. Kapiteijn E, Marijnen CA, Nagtegaal ID, Putter H, Steup WH, Wiggers $\mathrm{T}$, et al.: Preoperative radiotherapy combined with total mesorectal excision for resectable rectal cancer. $N$ Engl J Med 200I, 345:638-646.

5. Ortholan C, Francois E, Thomas O, Benchimol D, Baulieux J, Bosset $\mathrm{JF}$, et al.: Role of radiotherapy with surgery for $\mathrm{T} 3$ and resectable T4 rectal cancer: evidence from randomized trials. Dis Colon Rectum 2006, 49:302-310.

6. Bendardaf R, Lamlum H, Pyrhonen S: Prognostic and predictive molecular markers in colorectal carcinoma. Anticancer Res 2004, 24:2519-2530.

7. Sun XF, Zhang H: Clinicopathological significance of stromal variables: angiogenesis, lymphangiogenesis, inflammatory infiltration, MMP and PINCH in colorectal carcinomas. Mol Cancer 2006, 5:43.

8. Duff SE, Jeziorska M, Kumar S, Haboubi N, Sherlock D, O'Dwyer ST, et al.: Lymphatic vessel density, microvessel density and lymphangiogenic growth factor expression in colorectal cancer. Colorectal Dis 2007, 9:793-800.

9. Fleming ID CJHDHRKBMGeale: AJCC cancer staging manual 5th edition. Philadelphia: J.B.Lippincott; 1997.

10. Weidner N, Semple JP, Welch WR, Folkman J: Tumor angiogenesis and metastasis-correlation in invasive breast carcinoma. N Engl J Med I99I, 324:I-8.

II. Kumar A, Collins HM, Scholefield JH, Watson SA: Increased typeIV collagenase (MMP-2 and MMP-9) activity following preoperative radiotherapy in rectal cancer. $\mathrm{Br} J$ Cancer 2000, 82:960-965.

12. Stanciute D, Didziapetriene J, Kadziauskas ]: [Expression of matrix metalloproteinases in patients with malignant tumors]. Medicina (Kaunas) 2004, 40: I I 143-I I 50.

13. Wang JL, Sun Y, Wu S: Gamma-irradiation induces matrix metalloproteinase II expression in a p53-dependent manner. Mol Carcinog 2000, 27:252-258.

14. Speake WJ, Dean RA, Kumar A, Morris TM, Scholefield JH, Watson $S A$ : Radiation induced MMP expression from rectal cancer is short lived but contributes to in vitro invasion. Eur J Surg Oncol 2005, $31: 869-874$.

15. Baeten $\mathrm{Cl}$, Castermans K, Lammering G, Hillen F, Wouters BG, Hillen $\mathrm{HF}$, et al.: Effects of radiotherapy and chemotherapy on angiogenesis and leukocyte infiltration in rectal cancer. Int J Radiat Oncol Biol Phys 2006, 66: 1219-1227.

16. Gaugler MH, Squiban C, van der MA, Bertho JM, Vandamme M, Mouthon MA: Late and persistent up-regulation of intercellular adhesion molecule-I (ICAM-I) expression by ionizing radia- 
tion in human endothelial cells in vitro. Int J Radiat Biol 1997, 72:20I-209.

17. Kissane JH: Anderson's Pathology 9th edition. St.Louis, Baltimore, Philadelphia, Toronto: The CV Mosby Company; 1990.

18. Angenete E, Langenskiold M, Falk P, Ivarsson ML: Matrix metalloproteinases in rectal mucosa, tumour and plasma: response after preoperative irradiation. Int J Colorectal Dis 2007, 22:667-674.

19. Nirmala C, Jasti SL, Sawaya R, Kyritsis AP, Konduri SD, Ali-Osman F, et al:: Effects of radiation on the levels of MMP-2, MMP-9 and TIMP-I during morphogenic glial-endothelial cell interactions. Int / Cancer 2000, 88:766-77I.

20. Gallego MG: Vascular enumeration as a prognosticator for colorectal carcinoma. European Journal of Cance 2000, 36:55-60.

21. Zheng S, Han MY, Xiao ZX, Peng JP, Dong Q: Clinical significance of vascular endothelial growth factor expression and neovascularization in colorectal carcinoma. World J Gastroenterol 2003, 9:1227- 1230.

22. Shia J, Guillem JG, Moore HG, Tickoo SK, Qin J, Ruo L, et al.: Patterns of morphologic alteration in residual rectal carcinoma following preoperative chemoradiation and their association with long-term outcome. Am J Surg Pathol 2004, 28:2I 5-223.

\section{Pre-publication history}

The pre-publication history for this paper can be accessed here:

http://www.biomedcentral.com/1471-2407/9/95/prepub

Publish with Bio Med Central and every scientist can read your work free of charge

"BioMed Central will be the most significant development for disseminating the results of biomedical research in our lifetime. "

Sir Paul Nurse, Cancer Research UK

Your research papers will be:

- available free of charge to the entire biomedical community

- peer reviewed and published immediately upon acceptance

- cited in PubMed and archived on PubMed Central

- yours - you keep the copyright 